\title{
Licorice induced pseudohyperaldosteronism, severe hypertension, and long QT
}

\author{
Stine Bech Smedegaard ${ }^{1}$ and Mads Vandsted Svart ${ }^{1,2}$ \\ 1Department of Internal Medicine, Horsens Regional Hospital, Horsens, Denmark and 2Department of Internal \\ Medicine and Endocrinology (DoH), Aarhus University Hospital, Aarhus N, Denmark
}

Correspondence should be addressed to S B Smedegaard Email

stinsmed@rm.dk

\section{Summary}

Excessive intake of licorice may cause pseudohyperaldosteronism which, in turn, may lead to hypertension and hypokalemia. Severe hypokalemia may lead to electrocardiogram (ECG) changes including long QT interval potentially progressing into malignant arrhythmias. Here we present a 43-year-old woman admitted to the hospital with chest pain and a stinging sensation in the upper extremities. Her peak blood pressure was $177 / 98 \mathrm{mmHg}$ and the blood test revealed low plasma potassium of $1.9 \mathrm{mmol} / \mathrm{L}$. The ECG revealed flattened T-waves and long QT interval. Prior to admission, the patient had increased licorice ingestion to a total of some $70 \mathrm{~g}$ daily. The licorice intake was stopped and potassium was administrated orally and intravenously. Plasma potassium normalized and the ECG changes remitted. To our knowledge a few other cases of licorice-induced pseudohyperaldosteronism and long QT interval have previously been reported. This underlines the importance of quantifying licorice intake in younger people with unexplained high blood pressure and low potassium.

\section{Learning points:}

- Even small amounts of licorice daily may increase the risk of developing hypertension; therefore, licorice should be asked for specifically.

- Even though licorice intake is very easy to cover in the patient's history, it is often missed.

- Excessive licorice intake may course severe hypokalemia causing long QT interval in the ECG recording, potentially progressing into arrhythmias and even cardiac arrest/sudden death.

- Hypokalemia $<3 \mathrm{mmol} / \mathrm{L}$ and present ECG changes should be treated with potassium intravenously.

- Licorice-induced hypertension may be associated with syndrome of apparent mineralocorticoid excess (SAME). Plasma renin and aldosterone are both low at diagnosis and normalize when licorice is stopped.

\section{Background and introduction}

Excessive licorice intake is a well-known cause of hypertension. The licorice compound glycyrrhizin inhibits the enzyme 11-beta-hydroxysteroid dehydrogenase type two (11ß-HSD2), which is found in the kidney tubules. The enzyme inactivates cortisol to cortisone. Cortisol stimulates the mineralocorticoid receptor (MCR) and by inactivation of cortisol this stimulation is reduced. When licorice inhibits $11 \beta$-HSD2, the cortisol level rises stimulating the MCR excessively. This, in turn, leads to resorption of sodium, secretion of potassium, and increase in blood pressure. The condition mimics high levels of mineralocorticoids known as pseudohyperaldosteronism (PsHA) or syndrome of apparent mineralocorticoid excess (SAME) (1). Severe hypokalemia may trigger electrocardiogram (ECG) changes such as arrhythmias, flattened T-waves, long QT interval, and ultimately cardiac arrest/sudden death (2).

This case report emphasizes that licorice may induce pseudohyperaldosteronism, hypertension, hypokalemia, 
Table 1 Blood test.

\begin{tabular}{|c|c|c|c|c|}
\hline Analysis & Unit & $\begin{array}{c}\text { Reference } \\
\text { range }\end{array}$ & Day 1 & Day 13 \\
\hline $\mathrm{K}^{+}$ & mmol/L & $3.5-4.6$ & 1.9 & 4.5 \\
\hline $\mathrm{Na}^{+}$ & mmol/L & $137-145$ & 143 & 141 \\
\hline Magnesium & $\mathrm{mmol} / \mathrm{L}$ & $0.70-1.10$ & 0.84 & 0.85 \\
\hline Creatinine & $\mu \mathrm{mol} / \mathrm{L}$ & $45-90$ & 80 & 81 \\
\hline CRP & $\mathrm{mg} / \mathrm{L}$ & $<8.0$ & 52.9 & - \\
\hline Leucocytes & *109/L & $3.5-10.0$ & 5.58 & - \\
\hline Renin & *10-3 IU & - & - & 11.9 \\
\hline Aldosterone & pmol & - & - & 140 \\
\hline Aldosterone/renin & $\mathrm{nmol} / \mathrm{IU}$ & $<31.0$ & & 11.8 \\
\hline
\end{tabular}

Abnormal values are presented in bold face.

CRP, C-reactive-protein; $\mathrm{Na}^{+}$, sodium; $\mathrm{K}^{+}$, potassium.

and ECG changes. The diagnosis is easily missed as the intake of licorice should be asked for specifically when covering the patient's history.

\section{Case presentation}

A 43-year-old female with a medical history of hypertension and myxedema was admitted to the Regional Hospital of Horsens, Denmark, with flu-like symptoms, chest pain, and a stinging sensation in both upper extremities. The symptoms were alternating present 14 days prior to admission. Everyday medication included three antihypertensive medications (beta block, angiotensinconverting enzyme (ACE) inhibitor in combination with a thiazide-like diuretic): metoprolol $50 \mathrm{mg} \times 1$ and perindopril $1.25 \mathrm{mg} \times 1+$ indapamid $5 \mathrm{mg}$. Previously, she was treated with four different types of antihypertensive medications. The physical examination and vital signs revealed no abnormalities except from a high blood pressure $(160 / 81 \mathrm{mmHg})$ and a temperature of $39^{\circ} \mathrm{C}$. An influenza test was positive. There was no vomiting. Blood tests revealed severe hypokalemia of $1.9 \mathrm{mmol} / \mathrm{L}$, elevated $\mathrm{C}$ reactive protein, and normal white blood cell count, the latter being compatible with viral infection (Table 1). The ECG showed sinus rhythm, no signs of ischemia, but a significant long QT interval, QTc $=476 \mathrm{~ms}$ (cutoff points for women $\leq 450 \mathrm{~ms}$ (normal), 451 to $470 \mathrm{~ms}$ (borderline), and $>470 \mathrm{~ms}$ (prolonged) (3)). The ECG also showed flattened T-waves (Fig. 1). Telemetry revealed no arrhythmias. The patient had consumed licorice sweets and been drinking licorice tea regularly for many years. Three weeks prior to admission this intake was increased to around $480 \mathrm{~g}$ of licorice sweets per week.

The combination drug indapamid+perindopril was paused as hypokalemia was initially suspected to be a side

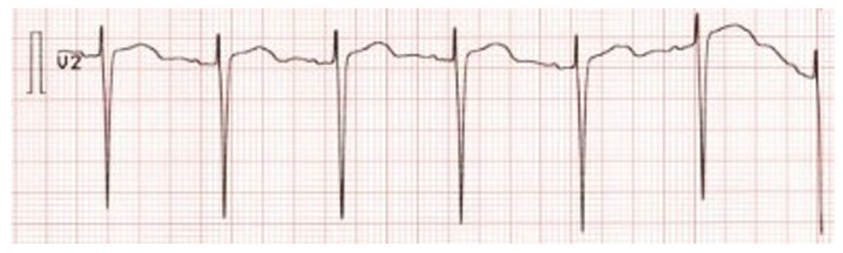

Figure 1

ECG at admission with flattened T-waves and long QT. ECG recording: 25 $\mathrm{mm} / \mathrm{s}, 10 \mathrm{~mm} / \mathrm{mV}$.

effect to indapamid (a thiazide-like drug). She was treated with $292 \mathrm{mmol}$ potassium orally and intravenously for the first $24 \mathrm{~h}$ of admission. Despite the great amount of potassium, p-potassium only increased to $2.6 \mathrm{mmol} / \mathrm{L}$. The following 4 days, she received another $362 \mathrm{mmol}$ potassium-normalizing p-potassium to $3.4 \mathrm{mmol} / \mathrm{L}$ (1st $24 \mathrm{~h}$ : $7500 \mathrm{mg}$ potassium chloride tablets (100 $\mathrm{mmol})$, $90 \mathrm{mmol}$ potassium chloride oral suspension, 1 liter Potassium-Sodium-Glucose infusion $(51 \mathrm{mmol})$ and 1 liter Potassium-Sodium-Chloride infusion (51 mmol) $\rightarrow$ P-potassium $2.6 \mathrm{mmol} / \mathrm{L}$. 2nd-4th day: 1 liter PotassiumSodium-Glucose infusion (51 mmol), 1 liter PotassiumChloride-Glucose infusion (51 mmol), in total 19,500 mg potassium chloride tablets $(260 \mathrm{mmol}) \rightarrow$ P-potassium 3.4 $\mathrm{mmol} / \mathrm{l}$. 5th day and on: potassium chloride $2250 \mathrm{mg} \times 2$ tablets (60 mmol)) (Fig. 2). The paresthesia eased within the first $24 \mathrm{~h}$. She was discharged from the hospital with p-potassium of $3.4 \mathrm{mmol} / \mathrm{L}$ and continued oral treatment with potassium chloride $2250 \mathrm{mg} \times 2$ until follow-up in the outpatient clinic of endocrinology. Here the medication was adjusted.

The peak blood pressure during admission was 177/98 mmHg. The high blood pressure and hypokalemia together with the history of increased intake of licorice led to the diagnosis of PsHA alternatively primary hyperaldosteronism (PHA). The antihypertensive drugs were changed in order to examine for the tentative diagnosis (see Discussion).

Two weeks after discharge p-renin, p-aldosterone and aldosterone/renin ratio were all normal and PHA was ruled out (Table 1). The blood pressure lowered to $128 / 86 \mathrm{mmHg}$, and the antihypertensive regimen was reduced to monotherapy with losartan $50 \mathrm{mg} \times 1$. Further, she was advised to stop using oral contraceptives. A new ECG showed normalization of the QT interval (QTc $=394$ ms) (Fig. 3). P-potassium was monitored for 5 weeks after discharge, and potassium chloride was stepwise reduced to $750 \mathrm{mg} \times 1$. She then transferred back to her general practitioner for further adjustment of the antihypertensive medication and potassium chloride. 


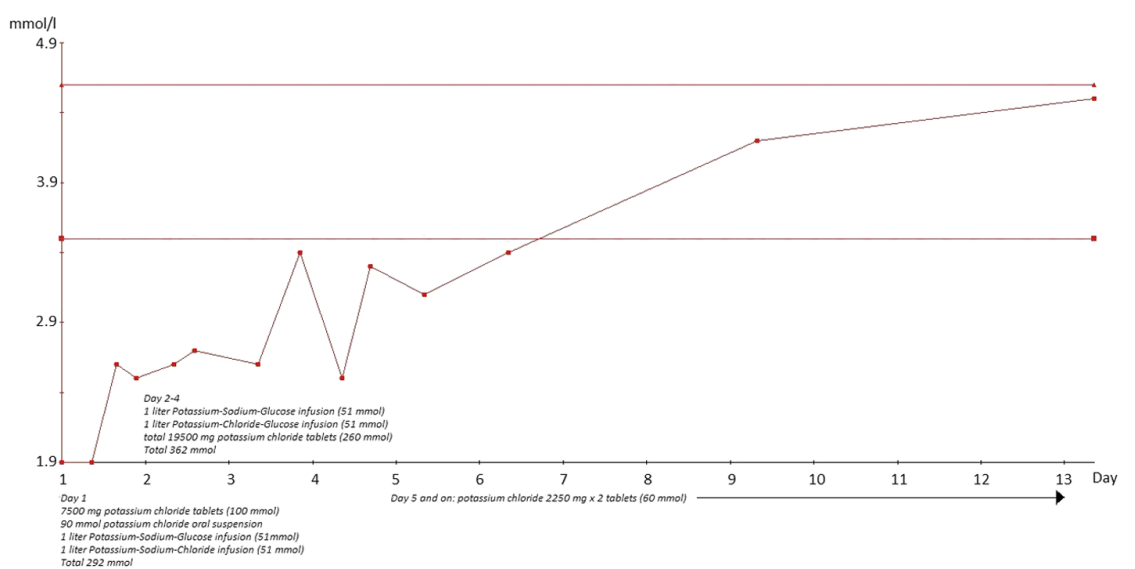

Figure 2

P-Potassium at admission day (day 1) to day 13 after starting substitution with potassium.

\section{Discussion}

Here we present a case of licorice-induced PsHA/SAME. The female patient had increased her licorice intake 3 weeks prior to admission presenting with symptoms comprising of chest pain, paresthesia, and deranged wellbeing. She had low p-potassium, flattened T-waves, and long QT interval in the ECG. Potassium levels were corrected and the licorice intake was stopped. The ECG normalized, blood pressure dropped, and antihypertensive treatment was heavily reduced.

The patient had ingested about $70 \mathrm{~g}$ of licorice daily and had also been drinking licorice tea (unknown amount). Even as little as $50 \mathrm{~g}$ of licorice (75 $\mathrm{mg}$ glycyrrhetinic acid) daily may increase the risk of hypertension (4).

The patient presented with long QT interval in the initial ECG. To our knowledge, only a few other cases of excessive licorice intake and long QT interval have been reported $(5,6)$. It is of great importance to recognize long QT interval in the ECG as it may lead to torsades the point, ventricular fibrillation, and even cardiac arrest/ sudden death $(3,6)$. According to guidelines, treatment of hypokalemia depends on the presence of ECG changes and the severity of the hypokalemia. With present ECG changes, intravenous substitution is advised as opposed to no ECG changes where oral substitution is sufficient (7). In this case the long QT interval resolved after correcting p-potassium (Figs 1 and 3).

This case also demonstrates that great amounts of potassium are needed to correct levels of p-potassium, and it illustrates the massive depletion of intracellular potassium due to licorice-induced PsHA. From guidelines the need to correct severe hypokalemia is usually $40-100$ mmol potassium per day (8). Our patient was hospitalized for 4 days until the potassium level was sufficiently corrected. During hospitalization she received an average of $163.5 \mathrm{mmol}$ per day. P-potassium drops approximately $0.3 \mathrm{mmol}$ for every $100 \mathrm{mmol}$ whole body potassium depletion (7). This estimates a deficit of some $500 \mathrm{mmol}$ in our patient on top of $40 \mathrm{mmol}$ daily to ensure normal potassium homeostasis (9) leading to a total need of $660 \mathrm{mmol}$ during the first 4 days of hospitalization. The estimate corresponds well to the $654 \mathrm{mmol}$ she received during hospitalization. Despite correction of p-potassium, an increased daily intake of potassium was still needed after 4 days of treatment, as it takes time for PsHA to resolve.

The patient was previously examined at the department of nephrology (2010) and at the department of cardiology (2014) because of hypertension and young age trying to cover causes of secondary hypertension. Hypertension and hypokalemia are symptoms of PHA and PsHA. P-renin and p-aldosterone are both low when suffering from PsHA/SAME (1) as opposed to PHA where p-renin is low and p-aldosterone is high (10). Many antihypertensive drugs interfere with the renin-angiotensin-aldosterone system. Therefore, most antihypertensive drugs must be paused for about four weeks for example thiazides and licorice must be paused. Only a few antihypertensive drugs are suitable without pause including $\alpha$-receptor antagonists and non-dihydropyridin calcium antagonists. Furthermore, p-potassium must be within normal range

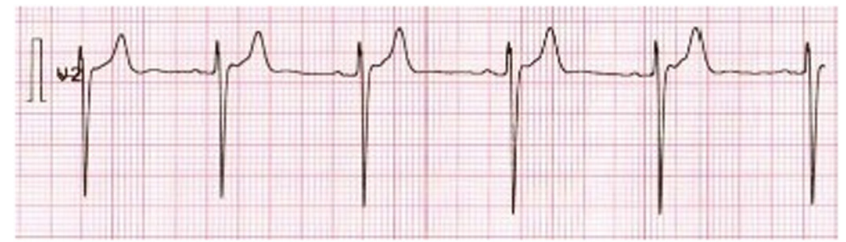

Figure 3

ECG 3 weeks after discharge with normal T-waves and QT interval. ECG recording: $25 \mathrm{~mm} / \mathrm{s}, 10 \mathrm{~mm} / \mathrm{mV}$. 
when measuring renin, aldosterone, and aldosterone/ renin ratio (10). All were normal at follow-up examination whereby PHA was ruled out and PsHA was found to be the most likely diagnosis. The patient was treated with indapamid (a thiazide-like drug) prescribed in a moderate dose prior to admission. It is a common drug used to treat hypertension. The hypokalemia in this case was severe and we therefore consider the PsHA diagnosis more likely than a side effect to indapamid.

Finally, the case highlights the importance of a sufficient and detailed patient history. Our patient was previously prescribed four different antihypertensive drugs and was examined in two different specialized hospital departments. If licorice intake came to attention by asking, one could speculate, that the antihypertensive medication and examination in specialized units could have been avoided.

\section{Declaration of interest}

The authors declare that there is no conflict of interest that could beperceived as prejudicing the impartiality of this case report.

\section{Funding}

This research did not receive any specific grants from any funding agency in the public, commercial, or not-for-profit sector.

\section{Patient consent}

The authors would like to thank the patient for consenting to having this case reported. Written informed consent for publication of the patient's clinical details was obtained from the patient.

\section{Author contribution statement}

Both authors of this manuscript were the physicians of the patient and contributed equally to this writing.

\section{Acknowledgements}

The authors would also like to thank the Department of Internal Medicine in Horsens for their support.

\section{References}

1 Varma R \& Ross CN. Liquorice: a root cause of secondary hypertension. JRSM Open 2017 8. (https://doi. org/10.1177/2054270416685208)

2 Chua CE, Choi E \& Khoo EYH. ECG changes of severe hypokalemia. QJM: Monthly Journal of the Association of Physicians 2018111 581-582. (https://doi.org/10.1093/qjmed/hcy046)

3 Straus SM, Kors JA, De Bruin ML, van der Hooft CS, Hofman A, Heeringa J, Deckers JW, Kingma JH, Sturkenboom MC, Stricker BH, et al. Prolonged QTc interval and risk of sudden cardiac death in a population of older adults. Journal of the American College of Cardiology 200647 362-367. (https://doi.org/10.1016/j.jacc.2005.08.067)

4 Sigurjonsdottir HA, Franzson L, Manhem K, Ragnarsson J, Sigurdsson G \& Wallerstedt S. Liquorice-induced rise in blood pressure: a linear dose-response relationship. Journal of Human Hypertension 200115 549-552. (https://doi.org/10.1038/sj.jhh.1001215)

5 Campana A, Manzo M, Brigante M, Marrazzo N \& Melchiorre G. An unusual cause of cardiac arrest. Italian Heart Journal. Supplement 2003 4 510-513.

6 Crean AM, Abdel-Rahman SE \& Greenwood JP. A sweet tooth as the root cause of cardiac arrest. Canadian Journal of Cardiology 200925 e357-e358. (https://doi.org/10.1016/s0828-282x(09)70723-8)

7 Viera AJ \& Wouk N. Potassium disorders: hypokalemia and hyperkalemia. American Family Physician 201592 487-495.

8 Cohn JN, Kowey PR, Whelton PK \& Prisant LM. New guidelines for potassium replacement in clinical practice: a contemporary review by the National Council on Potassium in Clinical Practice. Archives of Internal Medicine 2000160 2429-2436. (https://doi.org/10.1001/ archinte.160.16.2429)

9 National Research Council Subcommittee on the Tenth Edition of the Recommended Dietary Aollowances. The National Academies Collection: Reports Funded by National Institutes of Health. Recommended Dietary Allowances, 10th ed. Washington (DC): National Academies Press, 1989.

10 Funder JW, Carey RM, Mantero F, Murad MH, Reincke M, Shibata H, Stowasser M \& Young WF. The management of primary aldosteronism: case detection, diagnosis, and treatment: an Endocrine Society clinical practice guideline. Journal of Clinical Endocrinology and Metabolism 2016101 1889-1916. (https://doi. org/10.1210/jc.2015-4061)

Received in final form 29 October 2019

Accepted 22 November 2019 